\title{
DATA MODELLING SOLUTION FOR REFLECTIVE EPORTFOLIO SYSTEM
}

\author{
Aleksandrs Gorbunovs \\ Distance Education Study Centre, Riga Technical University \\ Dainis Gorbunovs \\ Riga State Gymnasium No.1
}

Atis Kapenieks

Distance Education Study Centre, Riga Technical University

\begin{abstract}
An importance of creating of efficacious information systems, which would enhance learning outcomes, leads to development of appropriate models.Modelling process with further validation and verification of developed information system or technological solution is essential. This paper displays the considerations and efforts made to work out such model in a form of reflection stimulating and learning outcomes enhancing ePortfolio information system. The authors introduce architecture of developed system from a view of used technologies, system's algorithmic model and data model, as well its approbation results in Living Lab.
\end{abstract}

Keywords - Assessment, Data model, ePortfolio system, Reflection.

\section{Introduction}

It could be recognized that at the moment fundamentally comprehensive studies in the ePortfolio area do not exist, irrespective of pretty much narrowly directed publications, findings and opinions regarding adoption of ePortfolio systems in educational organizations. It is found that till now there were not realized evaluations related to efficiency of ePortfolio systems, which field experts recommend to measure based on evidences of system users' activities, marking out for reflection characterizing data (Haig et al., 2007).

For a few decades world scientists have been investigating education supportive ePortfolio technologies with an aim to harmonize e-learning technical, organisational and educational development. Meanwhile holistic perspective of ePortfolio systems' development is highly fragmented with distinctive tools, functions and implementation levels. Although ePortfolios conceptually could support human resources development in European Union and all over the world, most institutions struggle to define their own concepts, systems and tools. ePortfolio approach has several advantages - it promotes students activities in new abilities, commitments, knowledge, and skills that enable learners to act effectively, as well it encourages both learners and teachers engaging in study process, critical thinking and reflection, which would be difficult to achieve in traditional e-learning. At the same time it should be noted, that in spite of ePortfolio systems adoption in many organizations, fundamental findings is not made enough. Besides, considering lifelong learning challenges, the research question of further improvement of ePortfolio systems and identity tools, as well 
searching of new solutions to improve learners' competence levels, is raised. On this score it is very important to find new possible way out by improvement of existing technologies and information systems (Reilly, 2013).

\section{Modelling}

The model of created ePortfolio system basically is in line with characteristics of information systems and is built upon three basic processes (Laudon \& Laudon, 2007): data input, processing and output; than the feedback processes follow-on. It is planned that created model (Fig.1) should provide the input of system users' accomplishments in a form of homeworks into the ePortfolio system where they are processed within created groups of users: there are enabled downloading, processing and analysing processes of submitted homework files (it enhances critical thinking and reflection processes), assessment and self-assessment of obtained data (homework files), preparing suggestions for the improvement. After noted actions the model provides data output processes, ensuring a supply of the assessments and suggestions of the input data to the corresponding homework author. Based on findings and other group participants' given assessments and recommendations for further possible improvements, system user accordingly reflects on them and makes necessary activities for the improvement of his/her initially submitted homework and its re-submission input into the system.

Based on an assumption that extra scaffolding information system, represented here in the model of ePortfolio system, ought to additionally encourage, motivate and engage learners, a conformable learning scenario was composed, and students were asked to develop it further. Pursuant to given task to build up own business idea (the task of the course subject) students develop it in few stages or series. Students' individual homework development in each stage starts with background information and explanation of the theme. Students' collaborative learning during all stages is widely supported by teaching staff and peers within ePortfolio groups. Each new task is set against previous level of knowledge in particular field, as well successfully accomplished prior tasks. Instructors' and colleagues' assistance to other students in groups, emphasizing key elements of the task, and giving necessary advice, encouraging learners to think critically and reflect on risen suggestions, is crucial in scaffolding educational systems (Wood et al., 1976). To keep learners response time shorter, ePortfolio groups were formed in the sequence based on homework submission time. 


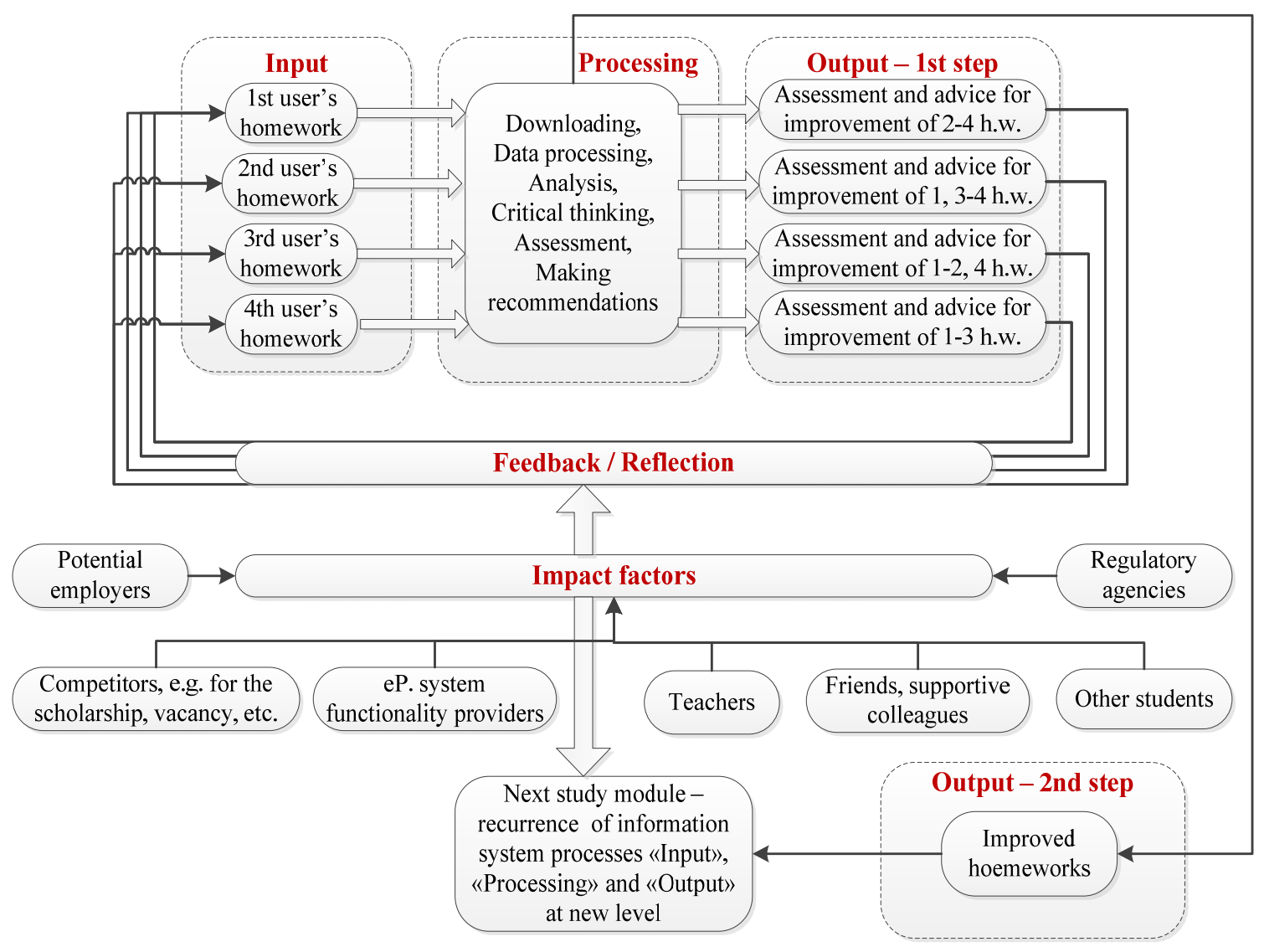

Figure 1 Reflection stimulating ePortfolio system model

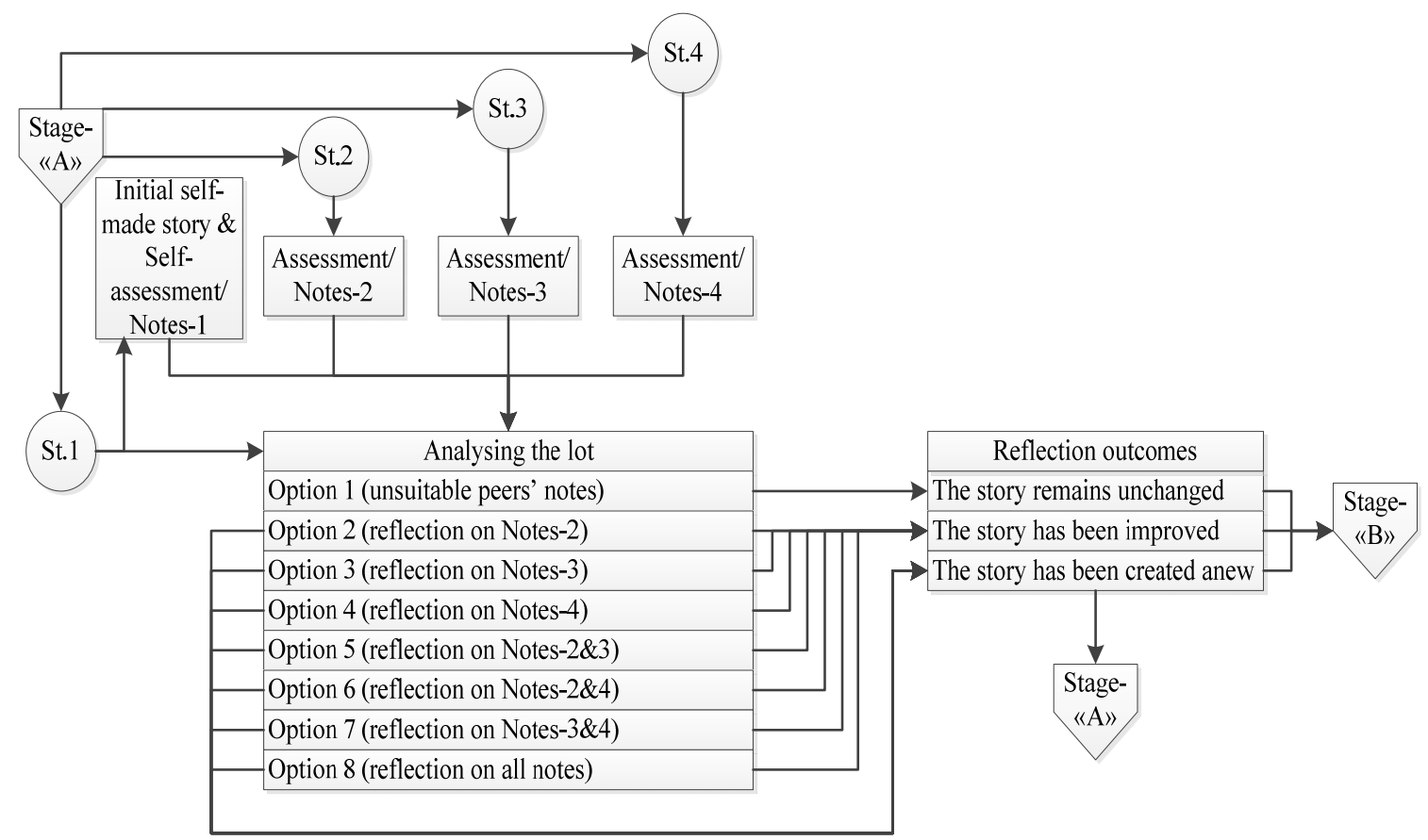

Figure 2 Reflection activation model( Gorbunovs et al., 2012b) 
Figure 2 in the view of flow diagram illustrates a part of the scenario for the first student, e.g. St.1, in the team of four learners. It shows possible scenario progressions (Gorbunovs et al., 2012b). Badges of the stages „A”, „B” etc. include already basic and advanced introduction into corresponding theme/stage, an instruction of follow-up tasks and actions following with students' homework and submission of draft papers. The first student can look at the critical thinking notes in the lot written by peers, analyse them and choose suitable option related to further work developments. The learner may use suggestions of one or more students, or decide to ignore them. The most important aspect here is that all students are involved in collaborative work and reflection. We hold a view that reflection is one of the key elements in competence development process. Introduced ePortfolio system enhances reflection and encourages students to think critically.

\section{Architecture, Algorithmic and Data Model of ePortfolioSystem}

It is necessary to specify that Riga Technical University's learning and e-content management system (LCMS) and created ePortfolio system are two independent information systems. Activities within ePortfolio system are available when system administrator or course tutor manually copies fulfilled homework files from the university's LCMS database to ePortfolio system (Gorbunovs, 2014). Before ePortfolio system enables any activities, students fulfil first assignments: take initial test to assess initial level of their competences, make self-appraisal and submit first homework. All these data go into university's LCMS database. After submission of the homework at the first onset the tutor inputs it to ePortfolio data base. Based on a time sequence of submitted homeworks, ePortfolio system forms groups of four students each.

ePortfolio system algorithmic model (Fig. 3) is tailored to the students homework files submission, own accomplished tasks self-appraisal and particular group participants homeworks assessment both in a form of marks in the scale from 1 to 10 (where 1 is the lowest assessment mark and $10-$ the highest one) and reflection expressions, e.g., suggestions, recommendations, which are displayed in textual form.

Based on peers made evaluation, the student takes the steps to improve own homework and proceeds to the next course module, or, if he/she decides that there is nothing to be improved in the homework, peers remarks are taken into account and the learner also proceeds to the next course module. In the case if the homework is improved, it will come to university's database for the additional reviewing. The model can provide also re-submission of improved files back to ePortfolio collaborative group-working environment. However, due to limited time schedule this option was not broadly applied. 


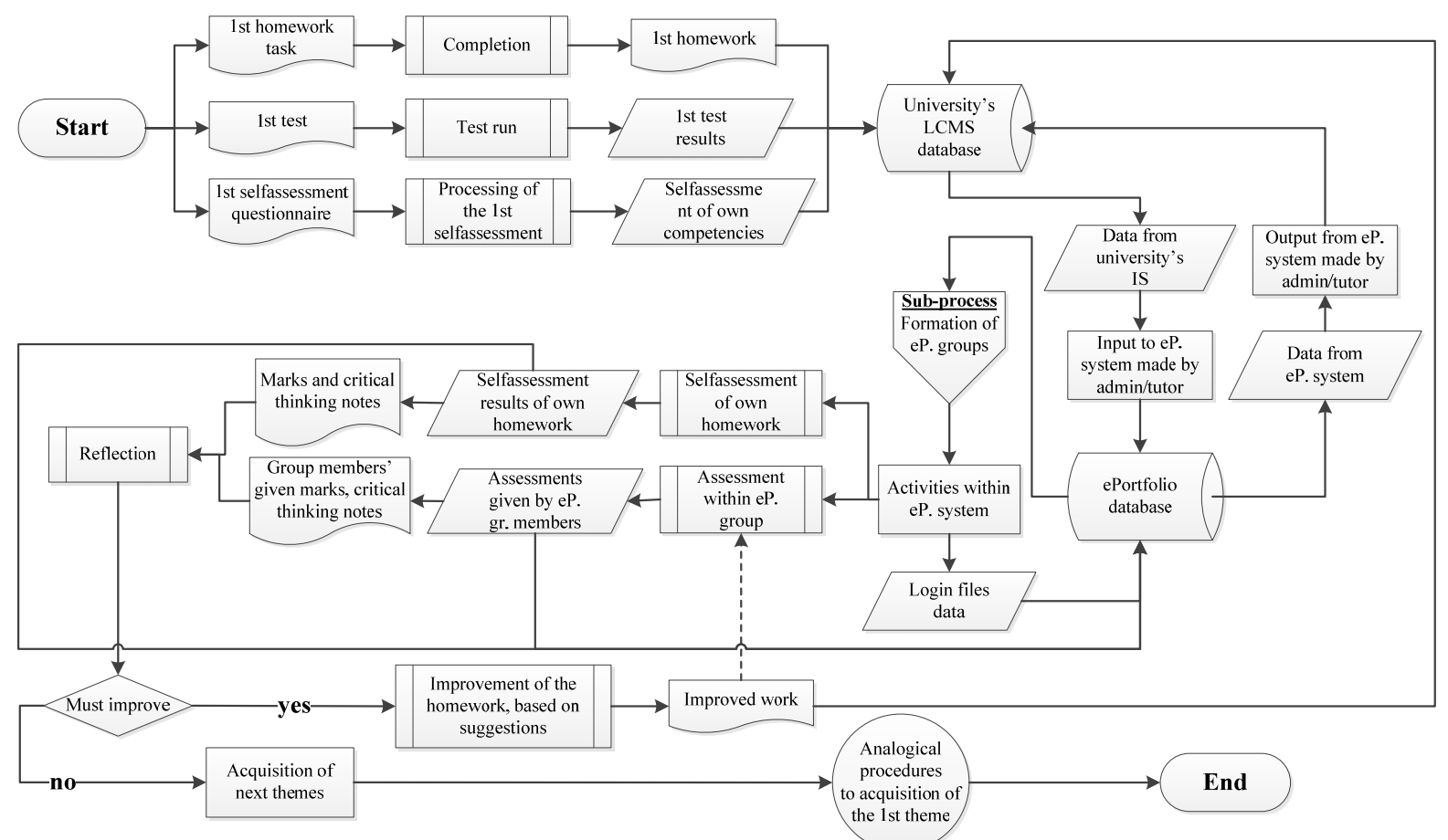

Figure 3 Algorithmic model (Gorbunovs, 2014)

Conceptual designis tailored to include ePortfolio system into joint motivating learning outcomes enhancing system:

- ePortfolio, onto scaffolding approach built on information system, which provides acquisition of new themes, based on previous learning modules and group-working activities within the system which empower improvement of critical thinking and reflection;

- University's LCMS 'ORTUS' where e-learning objects, as well selfassessments sites, e.g. tests and self-assessment questionnaires are placed.

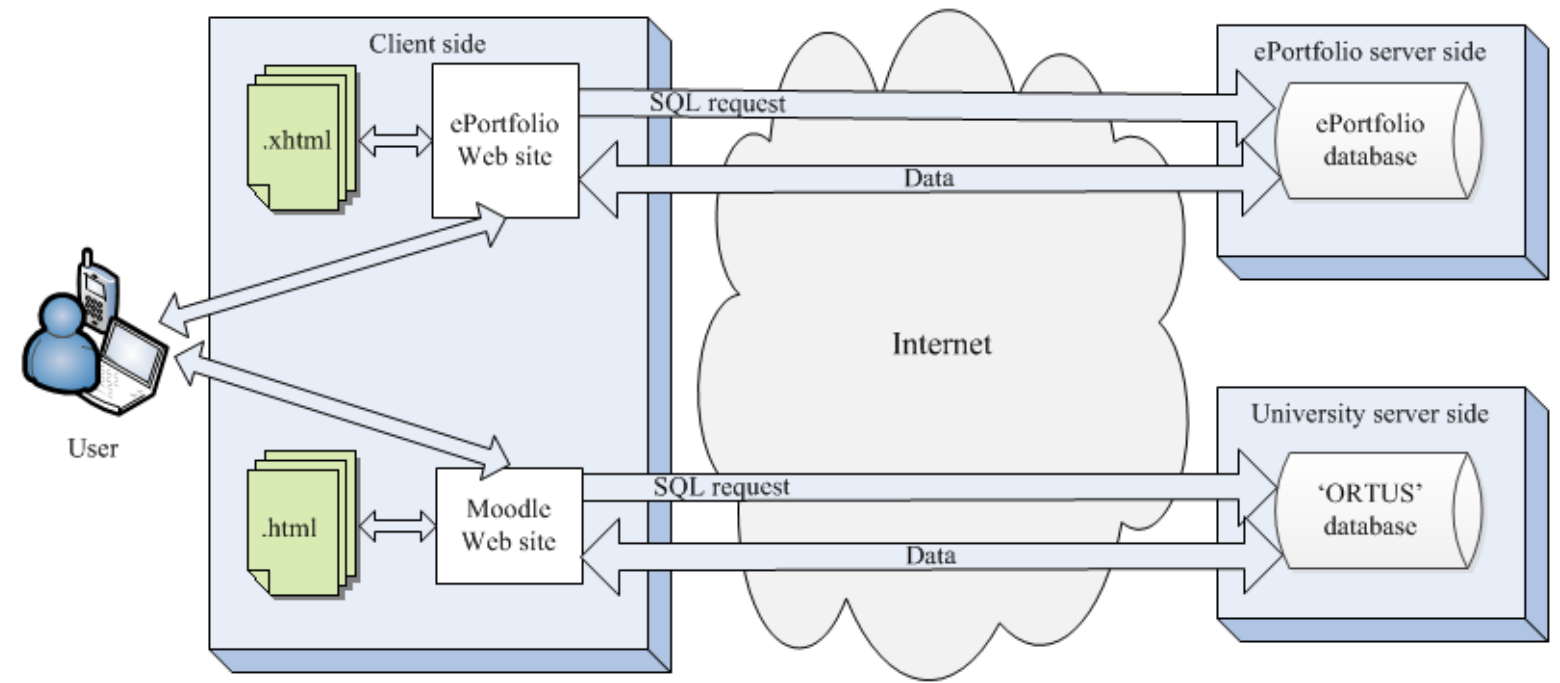

Figure 4 Architecture of the created information system from a view of used technologies 
Proposed ePortfolio system model is realized in the prototype of client-server form. FigureAn adumbration of the architecture of the created and existing information system (IS) from a view of used technologies is given in Figure4. Keeping in mind that university's LCMS and created ePortfolio system are two independent ISs, their client-server sides are separated, and request processes to servers' databases for each of them are organized apart.

In existing university's LCMS (at the bottom of the Fig.4) on the client side the user-student, to request the data (for instance, e-learning objects, records of lectures, presentations, own learning progress track records, and so on), communicates with the university's Moodle Web site by sending it the query, which makes SQL request to university's database. On the university's server side the database ("ORTUS") server realizes searching of requested data; further the university's Moodle Web site receives found data and presents they to the user-student. Sending of the data goes on also in the other way round - from the client side to the university server side, for instance, when the student submits requested homeworks. The user-teacher, in his/her turn, obtains students' submitted homework files by sending the query to the university's Web site which makes SQL request to university's database. On the client side there are files in HTML format which keep inwardly fragments of e-learning objects, tests, several formulations of the self-assessments, enforceable tasks, planned activities within ePortfolio system, etc.

In created ePortfolio system (on the top of the Fig.4) on the client side the userstudent, to request the data (for instance, particular system group partcipants homework files and assessments regarding own accomplished tasks given by other students of this group), communicates with the ePortfolio Web site by sending it the query, which makes SQL request to ePortfolio database. On the ePortfolio server side the database server responses/realizes searching of requested data; further the ePortfolio Web site receives found data and presents they to the user-student. Sending of the data goes on also in the other way round - from the client side to the ePortfolio server side, for instance, when the student makes self-assessment and realizes his/her ePortfolio system group participants' homework assessments. Consequently, ePortfolio system userstudent obtains necessary data to fulfil asked activities within the system, which enhance reflection and improvement of own accomplishments. The user-teacher realizes sending the data in the direction from the client side to ePortfolio server side when provides suggestions and comments to students for possible improvements of submitted files. On the ePortfolio client side there are files in XHTML format which keep inwardly description of executable tasks and activities within ePortfolio system, formulations of the assessment criterions, etc. 


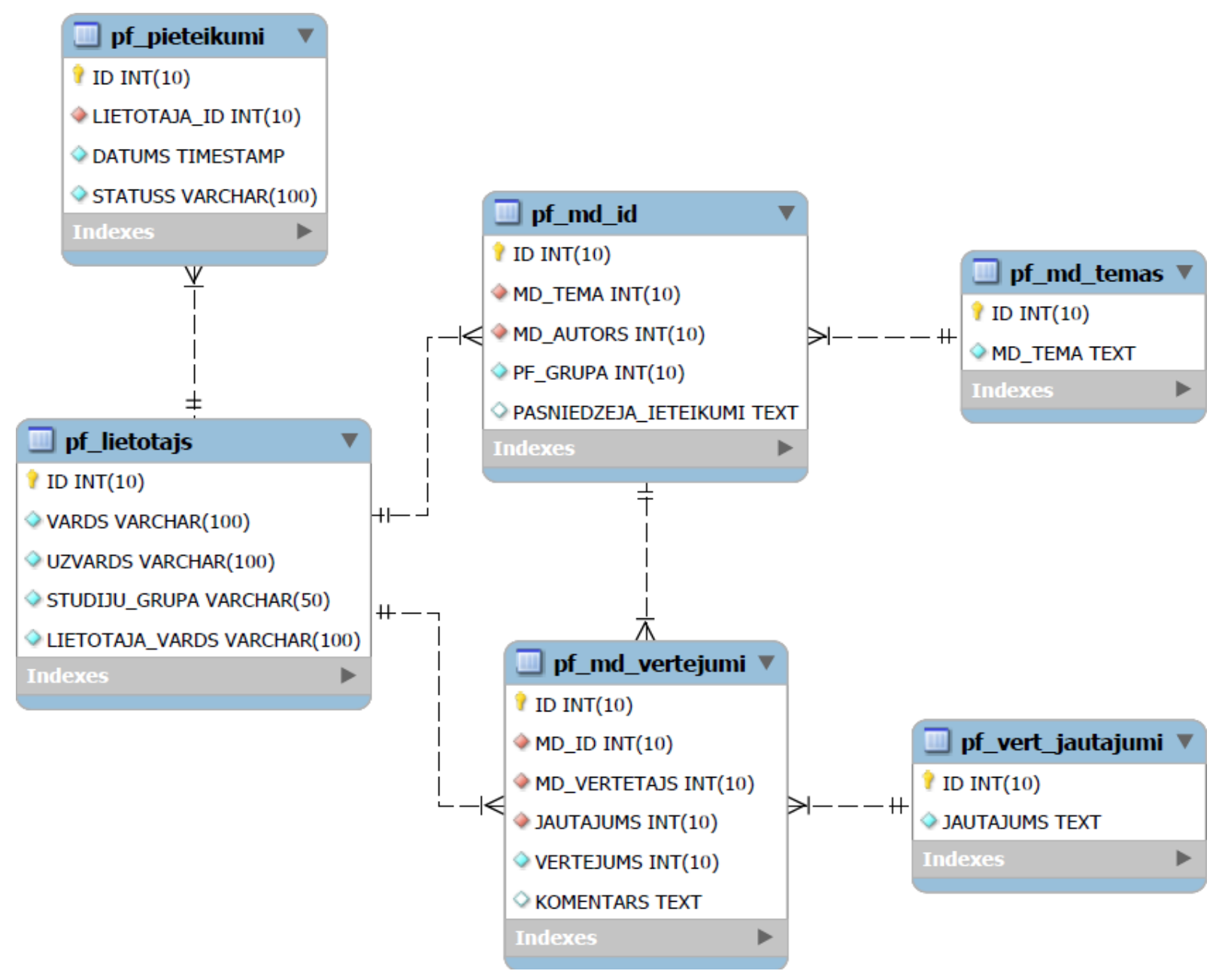

Figure 5 Data model

ePortfolio system data model is developed up by using of MySQL Workbench software. ePortfolio system database is realized by implementing of MySQL 5.5.16 database management system. It includes the tables as follows (Fig.5):

- The table „pf_lietotajs” keeps the data about students: ePortfolio system user's name (VARDS VARCHAR (100)), surname (UZVARDS VARCHAR (100)), university student's group number (STUDIJU GRUPA VARCHAR (50)) and username (LIETOTAJA VARDS VARCHAR (100)). This table hereafter in case of need could be increased with additional fields which would contain other student's descriptive attributes, for instance, e-mail address, phone number, and so on;

- The table „pf_pieteikumi” keeps ePortfolio system user's login and logout data: user's identifier (LIETOTAJA ID INT (10)), which is related to the ID of the table ,pf_lietotajs" about each login and logout in/to the system, their login and logout date and time (DATUMS TIMESTAMP), as well the login status within ePortfolio system (STATUSS VARCHAR (100));

- The table „pf_md_temas” keeps the themes names of fulfilled homework assignments (MD_TEMA TEXT); 
- The table ,pf_md_id" contains the data about user's fulfilled homeworks: homework identifier (MD_TEMA INT(10)) which is related to the ID of the table „pf_md_temas”, the identifier of fulfilled homework (MD_AUTORS INT(10)) which is related to the ID of the table ,pf_lietotajs”, ePortfolio group number (PF_GRUPA INT(10)), as well teacher's given recommendations for homework further improvement (PASNIEDZEJA_IETEIKUMI TEXT);

- The table „pf_vert_jautajumi” keeps the questions (JAUTAJUMS TEXT) to assess studentshomeworks;

- The table „pf_md_vertejumi” contains the data about assessment of usersstudents fulfilled homeworks: the identifier of the assessed homework (MD_ID INT(10)) which is related to the ID of the table ,pf_md id”, the identifier of the particular homework assessor (MD_VERTETAJS INT(10)) which is related to the ID of the table „pf_lietotajs”, the identifier of the assessment question (JAUTAJUMS INT(10)) which is related to the ID of the table „pf_vert jautajumi”, as well assessments given by ePortfolio group members in the form of marks (VERTEJUMS INT (10)) and suggestions (KOMENTARS TEXT).

\section{System Model's Assessment}

IntroducedePortfolio system model was successfully approbated in 2011-2013 academic years in Riga Technical University. To validate initially developed ePortfolio system model, an appropriate prototype was built. Considering that Living Lab research approach includes several research methods and consists of target-group identification, development of scenarios, creation of prototypes, estimation, interviews, group-working activities, surveys, feedbacks and studies of target-group activities (Fulgencio, 2012), and is defined as the environment where users validate new information and communication technology solutions (Følstad, 2008), this approach was chosen for the efficiency determination of created ePortfolio system.

By changing of ePortfolio system input parameters (namely - the number of activities within the system and log-files) the output parameters (namely - the number of improved homeworks - as the reflection characteristic feature, and exam results - as the competence levels development feature) were assessed, including statistical data analysis done by SPSS-21 software tools, all-in-all forming the validation and verification of the model and created system. System users' and field experts' survey results have also displayed the system's positive impact on learners reflection and competence development (Gorbunovs\& Kapenieks, 2012; Gorbunovs et al., 2012a, 2012b, 2013, 2014). 


\section{Conclusions}

Proposed ePortfolio system model enables involvement of all students in collaborative work, assessment and reflection activities. Reflection is one of the key elements in competence development process. Introduced ePortfolio system enhances reflection and encourages students to think critically.

Developed model ensures creation and functioning of reflection stimulating ePortfolio system which has direct impact on system users' critical thinking, reflection and achievements/learning outcomes. Validation and verification results give conclusive proof of positive impact of introduced ePortfolio system model and created prototypes on users' reflection, achievements and learning outcomes, comparing them with non-users data.

Embedded into ePortfolio system self- and peer-assessment tool facilitates feedback swell which becomes apparent in the main indicator of reflection - in increased number of task improved accomplishments.

Created ePortfolio system offers to its users learning outcomes' improvement tools which information systems of other higher educational institutions cannot provide. Proposed solution gives to the university the possibility to manage own ePortfolio system independently.

\section{Acknowledgements}

This work has been supported by the European Social Fund within the project «Support for the implementation of doctoral studies at Riga Technical University».

The authors are very grateful to M.sc.comp.InessaGorbunova, the head of ICT Department of the Latvian National Guard, Ministry of Defence, for hers constructive feedback regarding possible improvements of the data model and this paper.

\section{References}

1. Følstad, A. (2008). Living Labs for Innovation and Development of Information and Communication Technology: a Literature Review.The Electronic Journal for Virtual Organizations and Networks (eJOV), Vol. 10 (Special Issue on Living Labs), pp.99-131 / Internet [accessed 23.02.2010]. http://www.academia.edu/949819/Living_labs_for_innovation_and_development_of_in formation_and_communication_technology_a_literature_review

2. Fulgencio, H., Lefever, H., Katzy, B. (2012). Living Lab: Innovation through Pastiche. Proceedings of the eChallenges e-2012 Conference, Lisbon: IMC, pp.1-8.

3. Gorbunovs, A., Kapenieks, A. (2012). Competences Development Process Recording for Multi-Competence e-Course.Proceedings of the International Scientific Conference “Society, Integration, Education”, Rezekne, Vol. 1, pp.261-272.

4. Gorbunovs, A., Kapenieks, A., \&Kudina, I. (2012a). Competence Based Assessment Considerations within ePortfolio System. Proceedings of the 10th ePortfolio and 
Identity Conference „ePIC 2012”, London: ADPIOS, pp.132-142.8. / Internet [accessed 22.03.2013]. - http://www.epforum.eu/sites/www.epforum.eu/files/ePIC\%202012.pdf

5. Gorbunovs, A., Kapenieks, A., \&Kudina, I. (2012b). Competence Enhancement Scaffolding ePortfolio System.Proceedings of the 3rd International Workshop on Intelligent Educational Systems and Technology-enhanced Learning "INTEL-EDU 2012”, Riga: RTU, pp.65-78.

6. Gorbunovs, A., Kapenieks, A., Kudina, I. (2013).Advancement of e-portfolio system to improve competence levels.Proceedings of the International Scientific Conference “Society, Integration, Education”, Rezekne,Vol.1, pp. 61-72.

7. Haig, A., Beggs, K., Cadzow, A., Colthart, I., Hesketh, A., Peacock, H., Tochel, C. (2007). Efficacy of e-Portfolios: a Systematic Review of the Evidence.Proceedings of the 5th ePortfolio and Identity Conference ,ePIC 2007”, Maastricht: EIfEL, pp.20-22.

8. Gorbunovs, A. (2014). Reflective ePortfolio System: Development and Assessment in Living Lab.Proceedings of the 6th International Conference on Computer Supported Education CSEDU-2014, Barcelona: INSTICC, pp. 1-7.

9. Laudon, K., C., Laudon, J, P. (2007).Essentials of Business Information Systems (7thed.). Pearson: Prentice Hall. - pp.432.

10. Reilly, R. (2013). Information systems and technology: Existing solutions and innovation.Interview at the International Conference on Computer Supported Education CSEDU-2013,Aachen, 8 May, 2013.

11. Wood, D., Bruner, J., S., Ross, G. (1976). The role of tutoring in problem solving.Journal of Child Psychology \& Psychiatry \& Allied Disciplines, 17(2). Oxford, UK: John Wiley \& Sons. - pp.89-100.

PhD Candidate, Dipl.ing. \& M. sc.edu. Distance Education Study Centre, Riga

Aleksandrs Gorbunovs

Mr. Dainis Gorbunovs

Dr.phys. Atis Kapenieks
Technical University

e-mail: aleksandrs.gorbunovs_1@rtu.lv

Riga State Gymnasium No.1

e-mail: dainis.gorbunovs@gmail.com

Distance Education Study Centre, Riga

Technical University

e-mail: atis.kapenieks@rtu.lv 